\title{
Fatores essenciais de risco de uso de drogas por adolescentes: utilizando Modelagem de Equações Estruturais
}

\author{
Essential risk factors of drug use by adolescents: using Structural \\ Equation Modeling
}

http://dx.doi.org/10.5007/2178-4582.2016v50n1p209

Giovani Glaucio Costa

Universidade Federal Rural do Rio de Janeiro, Seropédica/RJ, Brasil

\begin{abstract}
$\mathrm{O}$ artigo visa contribuir para a identificação dos fatores gerais que facilitam o uso de drogas por adolescentes. Aponta os conceitos não observados diretamente relacionados aos fatores de risco diretos que aumentam a probabilidade do jovem vir a consumir drogas. A pesquisa, realizada com uma amostra de 124 psicólogos e assistentes sociais, questionou a percepção dos participantes acerca de 20 fatores de risco diretos relacionados ao consumo de drogas por adolescentes. Os dados foram submetidos a uma análise de confiabilidade, análise fatorial exploratória e modelagem de equações estruturais para verificar a existência de conceitos abstratos, identificá-los e confirmá-los. Verificouse que os fatores "Risco Natural", "Evento e Experiência de Vida" e "Social", nesta ordem, são os maiores facilitadores diretos do consumo de drogas por menores de idade. Os resultados preliminares abrem caminhos para estudos com amostras mais generalizáveis sobre a temática estudada.

Palavras-chaves: Uso de drogas por adolescentes; Análise de confiabilidade; Análise fatorial exploratória; Modelagem de equações estruturais.
\end{abstract}

This article aims to contribute to the identification of the general factors that facilitate the use of drugs by adolescents. It points out the concepts not directly observed related to the risk factors that increase the chances of drug use by young. The survey, conducted with a sample of 124 psychologists and social workers, questioned the participants' perception about 20 direct risk factors related to drug use by teenagers. The data were subjected to a reliability analysis, factor analysis and structural equation modeling to verify the existence of abstract concepts, identify them and confirm them. It was found that "Natural Risk", "Event and Life Experience" and "Social", in this order, are the most direct enablers factors of drug use by minors. Such preliminary results open the way for further studies with broader samples on the studied subject.

Keywords: Drug use by teenagers; Reliability analysis; Exploratory factor analysis; Structural equation modeling.

\section{Introdução}

Embora o uso de drogas por adolescentes seja alvo de muitos estudos, ainda não se chegou na literatura científica a um consenso sobre que fatores, especificamente, e suas inter-relações aumentam a probabilidade do adolescentes virem a consumir entorpecentes (ARTHUR et al., 2002).

A relação de fatores individuais de risco que ocasionam o uso de drogas por adolescentes, se combinados entre si, atingem mais de setenta possibilidades. Este cenário é um complicador para se produzir conhecimento plenamente evidente sobre o tema. Para agravar este fato, os pesquisadores estão identificando correlações entre vários fatores ainda não tão conhecidos, com a finalidade de chegar a um provável consenso sobre o uso de drogas pelos jovens (Id., Ibid.) . 
Características de personalidade do usuário, ou atributos pessoais de indivíduos que começam a usar álcool e tabaco desde cedo possuem maior tendência a usarem drogas em suas juventudes (ASSIS et al., 2003). São os chamados adolescentes-problema, que podem ser caracterizados por: terem baixo autocontrole; elevados níveis de procura de novidades; facilidade de assumir riscos; excesso de raiva; história de vida com eventos adversos; excesso de tolerância familiar por desvios de comportamento; excesso de independência; afeto negativo familiar.

De acordo com Assis et al. (2003), a violência e agressividade constituem fatores importantes no uso de drogas por adolescentes. Estes fatores resumem jovens indivíduos que se envolvem em agressões, pichações, porte ilegal de armas, pequenos roubos, alunos que abandonam a escola. Adolescentes com essas características possuem maior tendência a se envolverem com o uso de drogas (CHILCOAT1 ANTHONY, 1996). Segundo estes autores, características como violência, agressividade e os atributos pessoais de adolescentes-problemas são notados nos portadores de transtorno de conduta.

Jovens e adolescentes que sofrem de transtornos psiquiátricos - tais como, Transtorno do déficit de atenção e hiperatividade; Transtorno bipolar; Transtornos de ansiedade; Transtorno Borderline.; Tentativas de suicidio.; Transtornos de conduta; Transtorno de personalidade antissocial; Transtorno desafiador-opositor; Depressão maior - também tendem a usar drogas mais cedo e de forma mais compulsiva que jovens normais (DUCAN, 1971).

Existem estudos que indicam que o uso de uma determinada droga pode servir como automedicação para um indivíduo que apresente algum dos distúrbios acima citados, como, por exemplo, uma depressão maior, com o uso de álcool (ELLOCKSOR; MORTON, 1999). Ademais, o uso precoce de substâncias psicoativas mais pesadas como a cocaína, a heroína, o LSD e o Ecstasy é chamado por Kandel e Morton (1999) como "teoria da porta de entrada às drogas".

Alguns autores afirmam que o alcoolismo pode ter base genética, pois é frequente o caso de famílias nas quais mais de um de seus membros é alcoolista pesado De acordo com Francis (1985), existem importantes evidências notadas em famílias de origem oriental - como japoneses, chineses e coreanos - nas quais uma variante genética de uma das enzimas envolvidas no metabolismo do álcool (enzima chamada aldeído desidrogenase) é responsável pela síndrome doflushing, ou rubor facial, que se manifesta logo após a ingestão de álcool.

O grupo social no qual o adolescente está incluído é outro fator de risco: se os amigos usam drogas, há mais perigo de que o jovem venha a cair em tentação de experimentá-las, seguindo o exemplo de seus parceiros. A droga parece servir de aglutinador social para alguns adolescentes, os quais se drogam 
para fazer parte do grupo de amigos, seja este formado de colegas da escola, de clube ou da vizinhança (PATTON, 1995). Para este autor, o uso de substâncias proibidas vem da influência dos amigos e do grupo social ao qual o jovem adere, que é maior do que a influência dos pais e familiares no sentido de que seus filhos não usem drogas. Entretanto, Patton (Ibid.) também observa que aqueles jovens cujos familiares já usam substâncias têm mais oportunidades de acesso às drogas, e menos rigor familiar para com o uso inicial de cigarros e álcool, fato que pode levá-los mais cedo ao uso de outras drogas

Problemas familiares do tipo de divórcio ou separação dos pais, lares com apenas um dos membros, o pouco tempo que os pais dedicam à criação dos filhos, desemprego paterno, violência doméstica, e maus tratos aos filhos, favorecem o aparecimento de um núcleo familiar desestruturado e a procura do alívio pelos filhos problemáticos através do uso de drogas (PATTON, 1995).

Fatos que atingem a vida do adolescente como gravidez precoce, adoções mal resolvidas na infância, tentativas de violência sexual provocadas por parentes ou amigos da família também são fatores relevantes no uso de drogas por adolescentes, de acordo com Schenker e Minavo (2003). Ademais, ser semteto e passar fome, ser menino de rua nas grandes cidades brasileiras como São Paulo, Rio de Janeiro ou Recife são fatores dos mais importantes que levam os meninos e adolescentes miseráveis às drogas e ao tráfico (Ibid., 2003).

Muitos adolescentes, além de passarem fome, vivem com a constante falta de dinheiro para necessidades básicas e, assim, o tráfico surge como uma oportunidade. Os adolescentes entram no tráfico, em geral, porque buscam prestígio, virilidade, o poder de consumir, a visibilidade social. Não entram para acumular, mas para ter direito ao consumo - nesse sentido, paradoxalmente, os jovens empregados nessa atividade são os mais sensíveis ao sonho de inclusão social, vista, no caso, como inclusão no mercado (SCHENKER; MINAVO, 2003). No tráfico, ele tem a possibilidade de ser tratado em condições iguais aos adultos e o 'patrão' é mais justo, no plano da remuneração, do que a imensa maioria dos seus pares do mercado formal. Dessa forma o jovem recebe uma quantia maior do que a de um trabalhador honesto (Ibid.).

Quanto aos meios de comunicação, sua ligação comercial com os grandes anunciantes de bebidas e cigarros, as propagandas dirigidas ao público jovem, de modo aberto ou mesmo subliminar, colaboram para a difusão dos hábitos de beber ou de fumar dos adolescentes, desde cedo, e que, no futuro, poderão levá-los a experimentar outras drogas (DUCAN, 1971). Não há comerciais que deixem de ligar o fumar e o beber ao prazer, à juventude, ao belo e à vida saudável. São sempre dirigidos aos fumantes e bebedores de amanhã. Nunca apresentam o fumante e o alcoólico sofrendo com doenças que foram causa- 
das pelos hábitos adquiridos em suas juventudes. Não citam a possibilidade dos adolescentes que bebem e fumam desde cedo virem a se tornar dependentes químicos (Ibid.,1971).

A publicidade e a propaganda são responsáveis pelo desenvolvimento de um clima de aceitação geral a certas drogas, quer sejam utilizadas para fins terapêuticos, como vitaminas, analgésicos, xaropes, calmantes, quer sejam utilizadas para facilitar as relações sociais, melhorar o humor, e a descontração, como, por exemplo, o álcool e o fumo. A Organização Mundial da Saúde tem alertado todos os países quanto à divulgação indiscriminada de substâncias químicas pelos meios de mídia, fato que poderá levar a sociedade a resultados adversos, pois tende a camuflar a realidade, interferindo no desenvolvimento de uma vida equilibrada, saudável e natural (DUCAN, 1971).

Desse modo, de que adianta o governo mostrar, na mesma televisão que divulga o vício, propagandas antidrogas? Na Europa, já há muito tempo, é proibido anunciar na TV, no cinema, no rádio, em eventos públicos, na imprensa e em cartazes, álcool e cigarros. Somente são permitidas veiculações de comerciais de álcool e drogas lícitas após as 24 horas. Talvez no futuro, o Brasil também venha a adotar essa mesma política pública, hoje já em uso para o tabaco, e, a partir de então, possamos contar com a $\mathrm{TV}$, com o rádio e com a imprensa como aliados na luta pela prevenção ao uso de drogas em nosso país (DUCAN, 1971).

Até o momento não se conhece nenhum fator que, isoladamente, seja o determinante ou causador do uso, abuso ou dependência de drogas. Contudo, os fatores de risco ou de proteção não são determinantes; apenas aumentam, em diferentes intensidades, a probabilidade de o evento ocorrer (ARTHUR et al., 2002).

Este estudo realizou uma análise multivariada de interdependência dos fatores de risco diretos de adolescentes virem a consumir drogas ilícitas, com o objetivo de identificar quais os conceitos essenciais ou básicos, não observados diretamente, que possam resumir os fatores de risco que aumentam, em diferentes intensidades, a probabilidade de o evento ocorrer. Esta pesquisa visa avançar na contribuição no entendimento das correlações entre os vários fatores de risco para o uso de entorpecentes por adolescentes, com a finalidade de se chegar a um provável consenso sobre o uso de drogas pelos jovens.

\section{Materiais e métodos}

Este estudo trata de uma pesquisa de percepção de psicólogos e assistentes sociais acerca da intensidade - numa escala de 0 a 10 - da contribuição de cada fator individual no aumento ou redução da probabilidade do envolvimento de 
adolescentes com o uso de drogas. Os dados foram coletados no período de 2006 a 2014 e envolveram um "survey" de 124 psicólogos e assistentes sociais.

A amostragem utilizada no estudo foi a não probabilística por conveniência. Os profissionais do Departamento Geral de Ações Sócio-educativas (DEGASE), órgão do governo estadual que desenvolve políticas de atendimento ao adolescente em conflito com a lei, foram solicitados a opinarem quanto às suas percepções acerca dos níveis de risco de cada fator individual abordado neste estudo de determinarem o uso de drogas por adolescentes.

Tabela 1- Fatores individuais de risco de uso de drogas por adolescentes

\begin{tabular}{|c|c|}
\hline Variáveis & Descrição \\
\hline $\mathrm{X} 1$ & Terem baixo autocontrole \\
\hline $\mathrm{X} 2$ & Elevados níveis de procura de novidades \\
\hline X3 & Facilidade de assumir riscos \\
\hline $\mathrm{X} 4$ & Excesso de raiva \\
\hline X5 & $\begin{array}{l}\text { Excesso de tolerância familiar por desvios de comportamento, excesso } \\
\text { de independência }\end{array}$ \\
\hline $\mathrm{X} 6$ & Afeto negativo familiar \\
\hline $\mathrm{X} 7$ & Violência e agressividade \\
\hline $\mathrm{x} 8$ & Depressão maior \\
\hline X9 & Transtorno do déficit de atenção e hiperatividade \\
\hline $\mathrm{X} 10$ & Transtornos de ansiedade. \\
\hline $\mathrm{X} 11$ & Transtornos de conduta. \\
\hline $\mathrm{X} 12$ & Transtorno de personalidade anti-social \\
\hline $\mathrm{X} 13$ & Transtorno desafiador-opositor \\
\hline $\mathrm{X} 14$ & Os amigos usam drogas \\
\hline X15 & Uso de substâncias pelos pais, irmãos e demais familiares \\
\hline $\mathrm{X} 16$ & Problemas familiares do tipo de divórcio ou separação dos pais \\
\hline $\mathrm{X} 17$ & Gravidez precoce \\
\hline $\mathrm{X} 18$ & Adoções mal resolvidas na infância \\
\hline $\mathrm{X} 19$ & $\begin{array}{l}\text { Tentativas de violência sexual provocadas por parentes ou amigos da } \\
\text { família }\end{array}$ \\
\hline $\mathrm{X} 20$ & Ser sem-teto e passar fome, ser menino de rua \\
\hline
\end{tabular}

Fonte: elaborada pelo autor

Para atingir o objetivo de averiguar e identificar conceitos abstratos sumários causais do uso de drogas por adolescentes, a análise de desdobrará em três etapas:

$1^{\text {a) }}$ Realização de uma análise de confiabilidade para uma sondagem inicial do suporte do espaço de análise a diferentes fatores latentes ou conceitos não observados diretamente; 
$\left.2^{a}\right)$ Realização de uma análise fatorial exploratória para a emersão dos fatores latentes e assim criar as hipóteses teóricas para criação de um modelo relacional que traduza as relações dos fatores observáveis e seus constructos, que reflitam sumariamente a opinião dos técnicos quanto aos fatores de maior implicações no envolvimento de adolescentes com o uso de drogas;

$3^{\text {a }) ~ R e a l i z a c ̧ a ̃ o ~ d e ~ u m a ~ a n a ́ l i s e ~ f a t o r i a l ~ c o n f i r m a t o ́ r i a, ~ p o r ~ m e i o ~ d a ~ m o d e-~}$ lagem de equações estruturais, para validar o modelo teórico construído na $2^{\mathrm{a}}$ etapa analítica.

Nas próximas seções, o artigo fará um resumo de modelagem de equações estruturais e promoverá o desenvolvimento das fases da análise de dados.

\section{Resumo teórico de Modelagem de Equações Estruturais}

Tendo em vista a necessidade de que as pesquisas desenvolvidas sobre fenômenos psico-sociais se apóiem em metodologias capazes de refletir, na esfera das investigações empíricas, a complexidade que caracteriza as discussões teórico-conceituais, este artigo se propõe a oferecer uma visão genérica da Modelagem de Equações Estruturais (MEE).

A $M E E$ possui alto potencial de inter-relacionar conceitos e variáveis psicossociais, mas, por ser um método relativamente novo, tem sido ainda pouco utilizado nos estudos psicossociais no Brasil (BENTLER, 1989). De acordo com a descrição realizada acerca da $M E E$, evidenciou-se que tal método se caracteriza por especificar, estimar e testar relações hipotéticas entre um grupo de variáveis. Assim, podem-se estabelecer diversas relações de dependência entre variáveis, contemplando-se, inclusive, situações em que uma variável dependente em uma equação seja independente em outra (BYRNE, 1994).

Como a $M E E$ calcula relações causais entre todas as variáveis que compõem um modelo, é possível que se identifiquem quais são os fatores mais influentes no âmbito de um fenômeno sob estudo (DUCAN, 1971). Na MEE existe a possibilidade de que as variáveis sejam dispostas de modo intrincado dentro de um modelo, e esse aspecto abre espaço para que se venha a distinguir e a calcular os efeitos diretos, indiretos e totais que uma variável pode exercer sobre as demais. Frente a isso, tal metodologia apresenta-se capaz de explicar uma percentagem da variabilidade de cada uma das variáveis endógenas (dependentes) ao modelo (HOX, 1998).

Todas essas propriedades compõem a parte chamada de "submodelo" das relações estruturais, que integra um modelo de equações estruturais (Hoyle,1994). O outro "submodelo" constituinte de um modelo de equações estruturais é o de mensuração. É através dele que tal técnica comporta a inclusão 
de conceitos sociais abstratos, os quais são representados sob a forma de construtos ou variáveis latentes, elaborados com base na técnica da análise fatorial (KAPLAN, 2000).

Uma vez que o modelo tenha sido estimado e o seu ajuste aos dados empíricos tenha sido considerado satisfatório, através de vários testes de bondade do ajustamento que serão utilizados neste estudo (seção análise de dados e discussão dos resultados), a $M E E$ propicia também que as diversas correlações estabelecidas entre variáveis e construtos sejam expressas sob a forma de um diagrama (path diagran), o que possibilita uma representação mais clara e agradável da teoria estudada (KLEM, 2000).

Além disso, outro ponto a ser ainda notado é que os procedimentos de cálculos inerentes à $M E E$ levam em consideração as confiabilidades das variáveis, o que permite que se avaliem seus erros de mensuração (DUCAN, 1971). Nessa metodologia, tais erros são incluídos na modelagem na condição de variáveis não observáveis, de modo que suas magnitudes são estimadas e avaliadas. Dessa forma, são produzidos coeficientes "livres" da parcela de erro das medidas, o que os torna mais confiáveis (DUCAN, 1971).

Como indicam as características da $M E E$, esse método apresenta alguns traços distintivos em relação aos procedimentos tradicionais de análise multivariada (Ibid.). Em princípio, note-se que esse tipo de modelagem desenvolve uma análise confirmatória em vez de exploratória - apesar de que, em algumas etapas do processo de desenvolvimento de um modelo de equações estruturais, existe a possibilidade de se realizarem procedimentos de exploração dos dados. Em outras palavras, pesquisadores tendem a utilizar a $M E E$ para determinar se certo modelo é valido, em vez de usar tal técnica para "achar" um modelo que combina com os dados (HOYLE,1994). Nesse sentido, deve-se ressaltar que o conhecimento substantivo sobre o objeto estudado desempenha um papel fundamental como guia para a realização da maioria dos estágios do processo da modelagem (HOYLE,1994).

Por requerer que as relações entre variáveis sejam formuladas a priori (apesar de serem passíveis de modificações posteriores), tal técnica presta-se bem à análise de dados para propósitos inferenciais. Por contraste, outros procedimentos multivariados possuem natureza essencialmente descritiva (a exemplo da análise fatorial exploratória e da criação de indicadores psico-sociais), dificultando ou mesmo impossibilitando o teste de hipótese (KLEM, 2000).

Os procedimentos tradicionais multivariados são incapazes de avaliar ou corrigir erros de mensuração. A $M E E$, por seu turno, é capaz de prover estimativas explicitas desses parâmetros (KLEM, 2000). É justamente por incorporar e modelar os erros de mensuração que tal técnica gera estimativas não viesadas para as relações entre os construtos latentes (Ibid.). 
Ligada a esse aspecto está ainda outra diferença que deve ser frisada: enquanto os procedimentos clássicos de análise de dados modelam apenas as mensurações observáveis, análises feitas com base na $M E E$ incorporam tanto variáveis não-observáveis (latentes) quanto observáveis (BENTLER, 1989). Isso faz com que o uso de tal método seja recomendado em estudos que trabalham com conceitos abstratos (Ibid.).

Ainda que tenham sido ressaltados todos esses méritos da $M E E$, cabe notar que existem limites para a sua aplicação em análises de fenômenos psicossociais. Em princípio, deve-se colocar que essa técnica é fortemente dependente da variação dos elementos considerados (HOX, 1998). Com isso, seus resultados podem ser ofuscados quando se referem a populações marcadas por certa homogeneidade de características. Dito de modo mais específico, tal limitação refere-se à possibilidade de que relações teoricamente esperadas entre variáveis não se mostrem significantes no modelo empírico, caso os espectros de variação desses elementos sejam insuficientes (Ibid.).

Além disso, é necessário reforçar que a aplicação da $M E E$ mostra-se adequada apenas a abordagens que primem por captar a estrutura de fenômenos complexos. Nos casos de estudos que tenham propósitos mais simples, sem a preocupação de uma análise aprofundada dessa estrutura, métodos tradicionais podem ser mais propícios do que a MEE (Ibid.). Para averiguação da associação entre poucas variáveis observáveis, a regressão pode dar conta da tarefa sem que seja necessária uma sofisticada modelagem sobre as inter-relações dos fatores (Ibid.). Não se tem aqui, portanto, a pretensão de indicar a Modelagem de Equações Estruturais como um método quantitativo genericamente substitutivo aos tradicionais, mas como uma alternativa analítica para o avanço do estudo dos fenômenos sociais e biológicos como objetos complexos (HOX, 1998).

\section{Análise de dados e discussão dos resultados}

\section{Análise de Confiabilidade}

Tabela 2 - Coeficiente Alfa de Cronbach

Reliability Statistics

\begin{tabular}{|r|r|}
\hline $\begin{array}{c}\text { Cronbach's } \\
\text { Alpha }\end{array}$ & N of Items \\
\hline .961 & 20 \\
\hline
\end{tabular}

Fonte: elaborado em SPSS 15.0 
Se Alfa $\geq 0,5$, em valor absoluto, as variáveis da base de dados indicam conceitos latentes no espaço de análise. Pela tabela 2 , Alfa $=0,961$, uma confiabilidade admirável, isto implicando que a base de dados tem excelente confiabilidade: o espaço de partida comporta variáveis latentes e distintas bem definidas.

\section{Análise Fatorial Exploratória}

Tabela 3 - Teste de Esfericidade de Bartlett

\section{KMO and Bartlett's Test}

\begin{tabular}{|c|c|c|}
\hline \multicolumn{2}{|c|}{$\begin{array}{l}\text { Kaiser-Meyer-Olkin Measure of Sampling } \\
\text { Adequacy. }\end{array}$} & .956 \\
\hline $\begin{array}{l}\text { Bartlett's Test of } \\
\text { Sphericity }\end{array}$ & $\begin{array}{l}\text { Approx. Chi-Square } \\
\text { of } \\
\text { Sig. }\end{array}$ & $\begin{array}{r}5134.919 \\
190 \\
.000\end{array}$ \\
\hline
\end{tabular}

Fonte: elaborado em SPSS 15.0

A tabela 3 informa que o valor-p do teste de esfericidade de Bartlett é $0,000<0,05$, o que implica rejeitar a hipótese nula de que a matriz de correlação é a matriz identidade. Existem correlações suficientes entre as variáveis da base de dados que permita uma análise fatorial segura.

O valor do teste de KMO foi 0,956; admirável. Este resultado indica que o uso do método das componentes principais como indicadoras de variáveis latentes é excelente. Podem-se utilizar as componentes principiais como conceitos gerais que sumarizariam os fatores que facilitam o uso de álcool e drogas pelos adolescentes.

A tabela 4 informa valores bem acima de 0,5 para as comunalidades. Este resultado demonstra a fortíssima correlação das componentes principais às percepções dos especialistas sobre a intensidade dos fatores individuais aumentarem a probabilidade do adolescente vir a consumir drogas. 
Tabela 4 - Comunalidades

\begin{tabular}{|l|r|r|}
\hline & \multicolumn{1}{|c|}{ Initial } & Extraction \\
\hline $\mathrm{X} 1$ & 1.000 & .933 \\
$\mathrm{X}$ & 1.000 & .940 \\
$\mathrm{X}$ & 1.000 & .943 \\
$\mathrm{X} 4$ & 1.000 & .938 \\
$\mathrm{X} 5$ & 1.000 & .933 \\
$\mathrm{X6}$ & 1.000 & .932 \\
$\mathrm{X}$ & 1.000 & .943 \\
$\mathrm{X} 8$ & 1.000 & .935 \\
$\mathrm{X}$ & 1.000 & .936 \\
$\mathrm{X} 10$ & 1.000 & .940 \\
$\mathrm{X} 11$ & 1.000 & .943 \\
X12 & 1.000 & .937 \\
X13 & 1.000 & .931 \\
X14 & 1.000 & .982 \\
X15 & 1.000 & .981 \\
X16 & 1.000 & .983 \\
X17 & 1.000 & .945 \\
X18 & 1.000 & .950 \\
X19 & 1.000 & .937 \\
X20 & 1.000 & .932 \\
\hline
\end{tabular}

Fonte: Elaborado em SPSS 15.0

Método de extração: principal component analysis 
Tabela 5 - Total de Variância Explicada

\begin{tabular}{|c|c|c|c|c|c|c|c|c|c|}
\hline \multirow[b]{2}{*}{ Component } & \multicolumn{3}{|c|}{ Initial Eigenvalues } & \multicolumn{3}{|c|}{ Extraction Sums of Squared Loadings } & \multicolumn{3}{|c|}{ Rotation Sums of Squared Loadings } \\
\hline & Total & $\%$ of Variance & Cumulative \% & Total & $\%$ of Variance & Cumulative \% & Total & $\%$ of Variance & Cumulative \% \\
\hline 1 & 13.889 & 69.443 & 69.443 & 13.889 & 69.443 & 69.443 & 11.708 & 58.540 & 58.540 \\
\hline 2 & 3.142 & 15.709 & 85.152 & 3.142 & 15.709 & 85.152 & 4.110 & 20.550 & 79.090 \\
\hline 3 & 1.862 & 9.311 & 94.463 & 1.862 & 9.311 & 94.463 & 3.075 & 15.373 & 94.463 \\
\hline 4 & 141 & .704 & 95.167 & & & & & & \\
\hline 5 & 106 & .531 & 95.698 & & & & & & \\
\hline 6 & 103 & .513 & 96.212 & & & & & & \\
\hline 7 & . 091 & .455 & 96.667 & & & & & & \\
\hline 8 & .087 & .436 & 97.102 & & & & & & \\
\hline 9 & . 084 & .422 & 97.524 & & & & & & \\
\hline 10 & .074 & .370 & 97.894 & & & & & & \\
\hline 11 & 072 & .359 & 98.253 & & & & & & \\
\hline 12 & .061 & .307 & 98.560 & & & & & & \\
\hline 13 & .054 & .268 & 98.828 & & & & & & \\
\hline 14 & .049 & .245 & 99.072 & & & & & & \\
\hline 15 & .041 & .205 & 99.277 & & & & & & \\
\hline 16 & .040 & .201 & 99.478 & & & & & & \\
\hline 17 & .034 & 170 & 99.648 & & & & & & \\
\hline 18 & .029 & .145 & 99.793 & & & & & & \\
\hline 19 & . 022 & .112 & 99.905 & & & & & & \\
\hline 20 & .019 & .095 & 100.000 & & & & & & \\
\hline
\end{tabular}

Fonte: SPSS 15.0

Método de extração: principal component analysis

De acordo com a tabela 5 , os três primeiros fatores são maiores do que 1 e retêm juntos $\mathbf{9 4 , 5 \%}$ da variância total, o que sugere que as percepções dos especialistas sobre a intensidade dos fatores individuais aumentarem a probabilidade do adolescente vir a consumir drogas podem ser reduzidos a três conceitos gerais, que sumarizariam os fatores que facilitam o uso de drogas pelos adolescentes. Portanto, existem três constructos, não observados, que indicam resumidamente e essencialmente os fatores que facilitam o uso de álcool e drogas pelos adolescentes.

O scree plot (Gráfico 1) confirma a existência de três constructos, que explicam $94,5 \%$ da variação total da pesquisa de percepção. 
Gráfico 1 - Scree plot

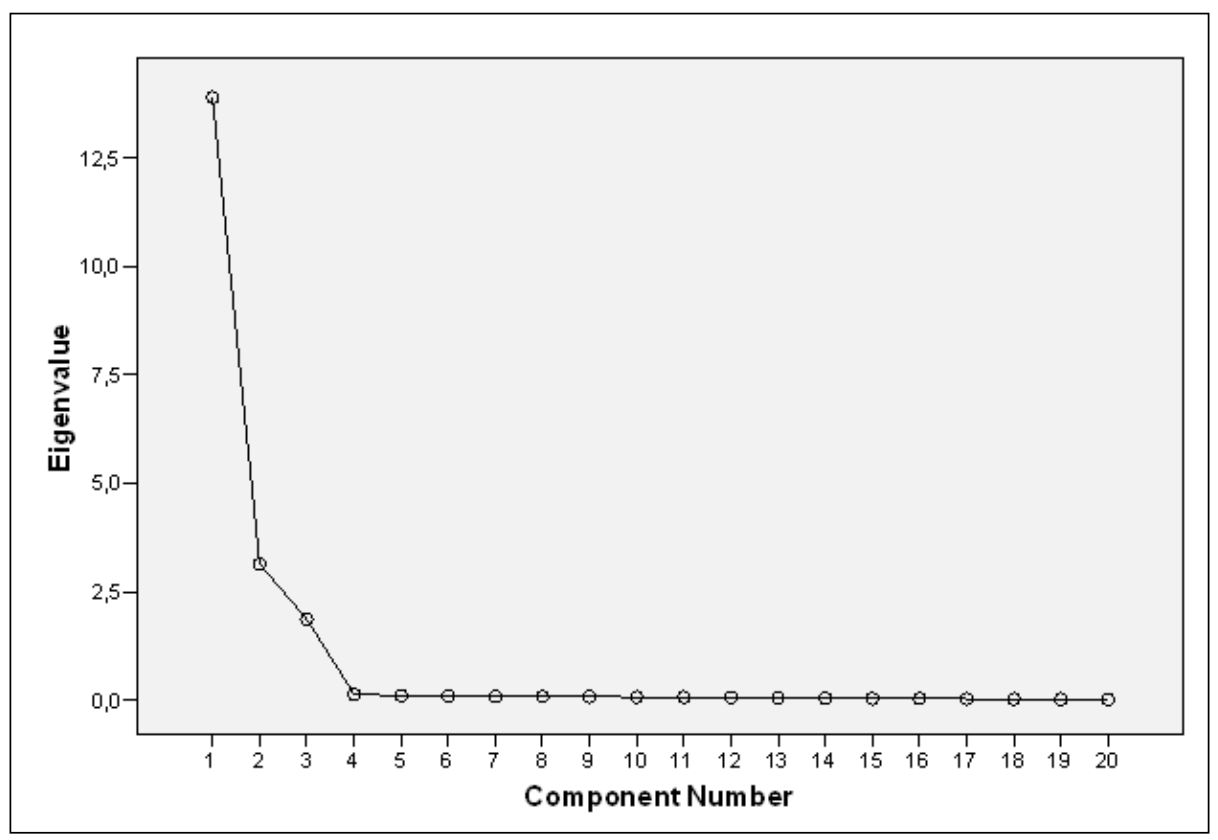

Fonte: SPSS 15.0

São exatamente três pontos, antes que a curva caia e se torne horizontal. Portanto, está ratificada a estruturação do espaço de análise em três novas dimensões. 
Tabela 6 -Matriz de Fatores

\begin{tabular}{|l|c|c|c|}
\hline & \multicolumn{3}{|c|}{ Component } \\
\cline { 2 - 4 } X1 & 1 & 2 & \multicolumn{1}{|c|}{3} \\
\hline X & .952 & .034 & -.158 \\
X3 & .956 & .025 & -.161 \\
X4 & .961 & .054 & -.124 \\
X5 & .960 & .003 & -.126 \\
X6 & .958 & .018 & -.121 \\
X & .953 & .055 & -.142 \\
X8 & .962 & .003 & -.132 \\
X9 & .950 & .057 & -.172 \\
X10 & .961 & .032 & -.104 \\
X11 & .961 & .003 & -.128 \\
X12 & .950 & .099 & -.178 \\
X13 & .960 & -.002 & -.124 \\
X14 & .950 & .067 & -.153 \\
X15 & .143 & .950 & .243 \\
X16 & .142 & .941 & .275 \\
X17 & .159 & .941 & .269 \\
X18 & .692 & -.441 & .521 \\
X19 & .705 & -.435 & .513 \\
X20 & .687 & -.143 & .667 \\
\hline
\end{tabular}

Fonte: SPSS 15.0 - método de extração: principal component analysis

a. 3 components extracted

As variáveis na tabela 6 apresentam estruturas complexas, ou seja, cargas fatoriais acima de 0,40 em mais de uma componente simultaneamente, caracterizando dupla pertence. As cargas fatoriais com essa configuração dificultam a interpretação dos fatores. A matriz rotada de fatores é um recurso que pode clarificar a busca dos fatores latentes. 
Tabela 7 - Matriz Rotada de Fatores

\begin{tabular}{|c|c|c|c|}
\hline & \multicolumn{3}{|c|}{ Component } \\
\hline & 1 & 2 & 3 \\
\hline$X 1$ & .930 & .254 & .056 \\
\hline$x 2$ & .934 & .256 & .047 \\
\hline$X 3$ & .926 & .280 & .087 \\
\hline$X 4$ & .922 & .294 & .038 \\
\hline$\times 5$ & .919 & .293 & .054 \\
\hline$x 6$ & .926 & .261 & .082 \\
\hline$X$ & .926 & .290 & .037 \\
\hline$x 8$ & .935 & .234 & .073 \\
\hline$x$ & .916 & .304 & .073 \\
\hline X10 & .923 & .293 & .038 \\
\hline X11 & .941 & .215 & .111 \\
\hline X12 & .920 & .298 & .035 \\
\hline X13 & .928 & .246 & .089 \\
\hline X14 & .092 & -.046 & .985 \\
\hline X15 & .078 & -.016 & .987 \\
\hline X16 & .096 & -.014 & .987 \\
\hline X17 & .377 & .876 & -.191 \\
\hline X18 & .392 & .873 & -.187 \\
\hline X19 & .330 & .900 & .137 \\
\hline X20 & .343 & .899 & .080 \\
\hline
\end{tabular}

Fonte: SPSS 15.0

Extraction method: principal component analysis

Rotation method: Varimax with Kaiser Normalization

a. Rotation converged in 5 interations

A tabela 7, matriz rotada de fatores, já indica quais são as variáveis latentes do espaço de análise. A Tabela 8 resume as variáveis importantes para cada fator e sua interpretação. 
Tabela 8 - Variáveis mais Importantes para cada Fator e Interpretação

\begin{tabular}{|c|c|c|c|}
\hline Fatores & Variáveis & Descrição & Interpretação \\
\hline \multirow{13}{*}{ Fator 1} & $\mathrm{X} 1$ & Terem baixo autocontrole & \multirow{13}{*}{$\begin{array}{l}\text { Fator de Risco } \\
\text { Natural }\end{array}$} \\
\hline & $\mathrm{X} 2$ & Elevados níveis de procura de novidades & \\
\hline & X3 & Facilidade de assumir riscos & \\
\hline & $\mathrm{X} 4$ & Excesso de raiva & \\
\hline & X5 & $\begin{array}{c}\text { Excesso de tolerância familiar por desvios } \\
\text { de comportamento, excesso de indepen- } \\
\text { dência }\end{array}$ & \\
\hline & X6 & Afeto negativo familiar & \\
\hline & $\mathrm{X} 7$ & Violência e agressividade & \\
\hline & $\mathrm{X} 8$ & Depressão maior & \\
\hline & X9 & $\begin{array}{l}\text { Transtorno do déficit de atenção e hipera- } \\
\text { tividade }\end{array}$ & \\
\hline & $\mathrm{X} 10$ & Transtornos de ansiedade. & \\
\hline & $\mathrm{X} 11$ & Transtornos de conduta. & \\
\hline & $\mathrm{X} 12$ & Transtorno de personalidade anti-social & \\
\hline & $\mathrm{X} 13$ & Transtorno desafiador-opositor & \\
\hline \multirow{3}{*}{ Fator 3} & X14 & Os amigos usam drogas & \multirow{3}{*}{ Fator Social } \\
\hline & X15 & $\begin{array}{c}\text { Uso de substâncias pelos pais, irmãos e } \\
\text { demais familiares }\end{array}$ & \\
\hline & X16 & $\begin{array}{l}\text { Problemas familiares do tipo de divórcio } \\
\text { ou separação dos pais }\end{array}$ & \\
\hline \multirow{4}{*}{ Fator 2} & $\mathrm{X} 17$ & Gravidez precoce & \multirow{4}{*}{$\begin{array}{l}\text { Fator Eventos e } \\
\text { Experiências de } \\
\text { Vida }\end{array}$} \\
\hline & X18 & Adoções mal resolvidas na infância & \\
\hline & X19 & \begin{tabular}{|c|} 
Tentativas de violência sexual provocadas \\
por parentes ou amigos da família \\
\end{tabular} & \\
\hline & $\mathrm{X} 20$ & $\begin{array}{c}\text { Ser sem-teto e passar fome, ser menino } \\
\text { de rua }\end{array}$ & \\
\hline
\end{tabular}

Fonte: Elaborado pelo autor 
Gráfico 2 - Gráfico das Variáveis

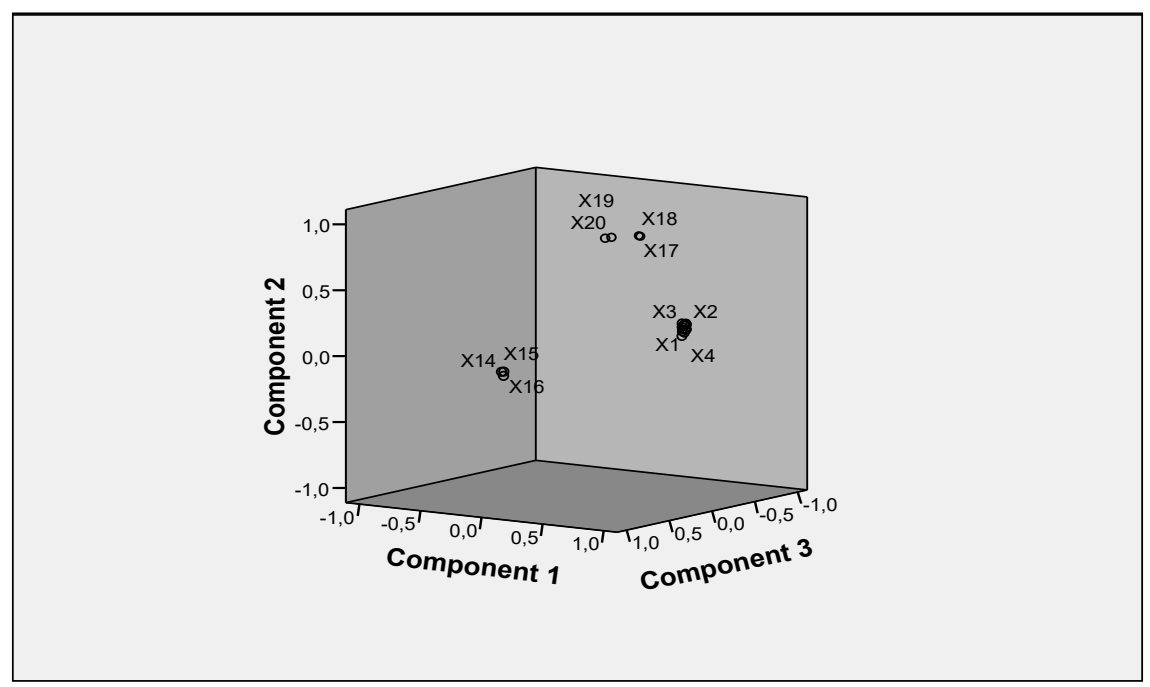

Fonte: SPSS 15.0

Pelo Gráfico 2, as variáveis $\mathrm{X}_{1}$ a $\mathrm{X}_{13}$ estão próximas da componente principal 1; as variáveis $\mathrm{X}_{17}$ a $\mathrm{X}_{20}$ estão juntas à componente principal 2; e, finalmente, as variáveis $\mathrm{X}_{14}$ a $\mathrm{X}_{16}$ estão convergindo à componente principal 3. Portanto, as variáveis latentes ou constructos não observados diretamente e que sumarizam os principais fatores que levam os jovens ao uso de drogas são de três tipos:

- Fatores de risco naturais.

- Fatores ligados a eventos e experiências da vida.

- Fatores de risco social.

Os Fatores de risco naturais respondem por $58,5 \%$ de as intensidades dos fatores individuais aumentarem a probabilidade do adolescente vir a consumir drogas. Os Fatores ligados a eventos e experiências da vida respondem por 20,6\%, enquanto Os Fatores de risco social respondem por 15,4\%.

É de fundamental importância o papel da família na formação do adolescente. É função das famílias fazer com que a criança aprenda a lidar com limites e frustrações. Alguns estudiosos afirmam que adolescentes desafiadores, que foram criadas sem regras, não aceitando limites impostos e que não sabem lidar com frustrações, apresentam maior risco para o uso de drogas. 


\section{Modelagem de Equações Estruturais}

Gráfico 3 - Fatores Individuais de Risco de Uso de Drogas por Adolescente

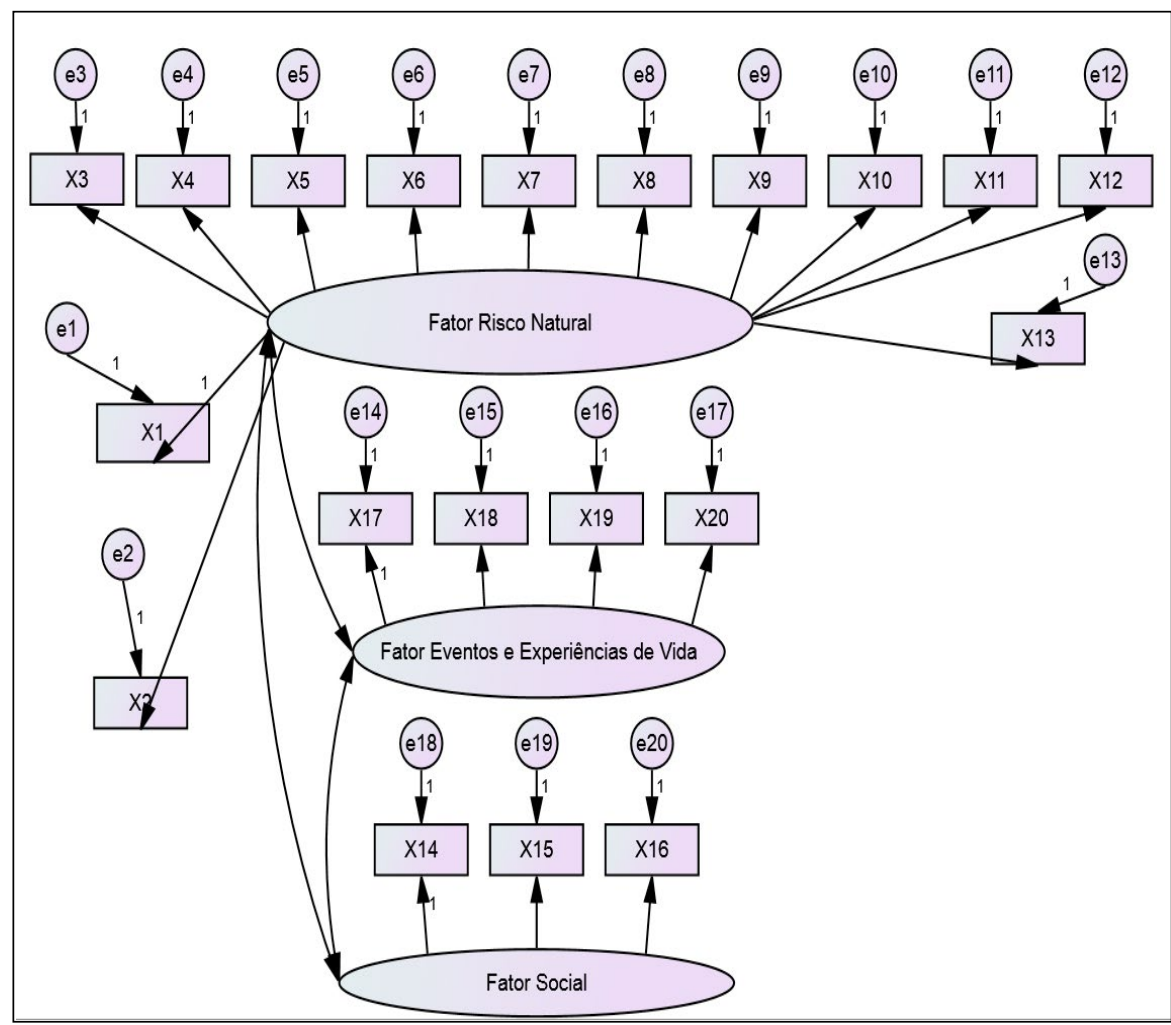

Fonte: AMOS 22.0

Com base no diagrama de caminhos (Gráfico 3), temos a seguinte teoria formulada para as inter-relações do espaço de análise:

- As variáveis latentes "Fatores de risco naturais", "Fatores ligados a eventos e experiências da vida" e "Fatores de risco social" são os constructos ou variáveis latentes e por hipótese com colinearidade;

- "Fatores de risco naturais" explicam as variáveis: Terem baixo autocontrole; Elevados níveis de procura de novidades; Facilidade de assumir riscos; Excesso de raiva; Excesso de tolerância familiar por desvios de comportamento; Excesso de independência; Afeto negativo familiar; Violência e agressividade; Depressão maior; Transtorno do déficit de atenção e hiperatividade; Transtornos de ansiedade; Transtornos de conduta; Transtorno de personalidade antissocial; Transtorno desafiador-opositor.

- "Fatores ligados a eventos e experiências da vida" explicam as variá- 
veis: Gravidez precoce; Adoções mal resolvidas na infância; Tentativas de violência sexual provocadas por parentes ou amigos da família; Ser sem-teto e passar fome, ser menino de rua;

- "Fatores de risco social" explicam as variáveis: Os amigos usam drogas; Uso de substâncias pelos pais, irmãos e demais familiares; Problemas familiares do tipo de divórcio ou separação dos pais.

Os erros de mensuração das variáveis endógenas foram inseridos na modelagem.

Este é o modelo construído com base em uma teoria sobre os conceitos abstratos que resumem a opinião das mulheres quanto aos seus desejos e anseios.

Tabela 9 - Resumo das Variáveis Especificadas 
Revista de Ciências HUMANAS, Florianópolis, v. 50, n. 1, p. 209-240, jan-jun 2016

$\begin{array}{ll}\text { Variable counts (Group number 1) } & \\ \text { Number of variables in your model: } & 43 \\ \text { Number of observed variables: } & 20 \\ \text { Number of unobserved variables: } & 23 \\ \text { Number of exogenous variables: } & 23 \\ \text { Number of endogenous variables: } & 20\end{array}$

Observed, endogenous variables $\mathrm{X} 1$

$\times 2$

$\mathrm{X} 3$

$\mathrm{X} 4$

$\times 5$

$\times 6$

$\times 7$

$\times 8$

$\times 9$

$\times 10$

$\mathrm{X} 11$

$\times 12$

$\times 13$

$\times 17$

$\times 18$

$\times 19$

$\times 20$

$\times 14$

$\times 15$

$\times 16$

Unobserved, exogenous variables Fator 1

e 1

e2

e3

e4

e5

e6

e7

e8

e9

e 10

e 11

e 12

e 13

Fator2

e 14

e 15

e 16

e17

Fator3

e 18

e19

e20 


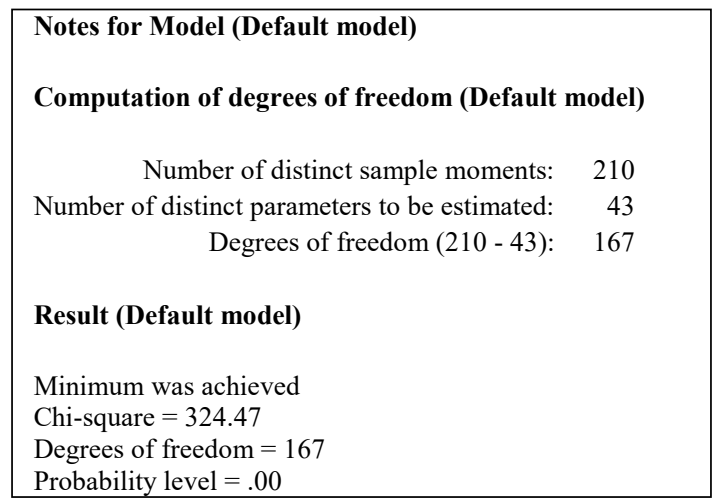

Fonte: AMOS 22.0

A tabela 9 informa as variáveis especificadas no modelo segundo seu papel na Modelagem de Equações Estruturais. Descreve também uma estatística das variáveis segundo esta natureza e os resultados da modelagem. Considerando o diagrama de caminhos do estudo, todas as variáveis observadas (percepções dos técnicos a cerca da intensidade de cada fator individual aumentar a probabilidade de um adolescente vir a usar drogas) são definidas como variáveis endógenas do modelo, ao passo que as variáveis latentes e os termos de erro são não observados, participando como variáveis latentes e exógenas da análise. O modelo tem 167 graus de liberdade e um valor - p para a bondade do ajustamento de $0 \%$, o que revelaria um mau ajustamento com $5 \%$ de significância.

Tabela 10 - Resumo dos Parâmetros do Modelo

\begin{tabular}{|l|cccccc|}
\hline & Weights & Covariances & Variances & Means & Intercepts & Total \\
\hline Fixed & 23 & 0 & 0 & 0 & 0 & 23 \\
Labeled & 0 & 0 & 0 & 0 & 0 & 0 \\
Unlabeled & 17 & 3 & 23 & 0 & 0 & 43 \\
Total & 40 & 3 & 23 & 0 & 0 & 66 \\
\hline
\end{tabular}

Fonte: AMOS 22.0 The model is recursive. Sample size: 124

A tabela 10 resume os parâmetros do modelo. Observe-se que há 40 pesos de regressão, dos quais 23 são fixos e 17 são estimados. O modelo é recursivo (quando as variáveis não são causas recíprocas umas das outras) e temos uma pesquisa de percepção com 124 técnicos (psicólogos e assistentes sociais).

Tabela 11 -Estimativas das Relações Causais do Modelo -Pesos de Regressão e 
Variâncias

Pesos de Regressão

\begin{tabular}{|lll|ccccc|}
\hline & & & Estimate & S.E. & C.R. & P & Label \\
\hline X1 & $<---$ & Fator1 & 1.00 & & & & \\
X2 & $<---$ & Fator1 & 1.00 & .03 & 28.66 & $* * *$ & par_1 \\
X3 & $<---$ & Fator1 & .96 & .03 & 29.04 & $* * *$ & par_2 \\
X4 & $<---$ & Fator1 & .99 & .04 & 28.34 & $* * *$ & par_3 \\
X5 & $<---$ & Fator1 & .98 & .04 & 27.79 & $* * *$ & par_4 \\
X6 & $<---$ & Fator1 & .98 & .04 & 27.61 & $* * *$ & par_5 \\
X7 & $<---$ & Fator1 & 1.00 & .03 & 29.12 & $* * *$ & par_6 \\
X8 & $<---$ & Fator1 & .99 & .04 & 27.75 & $* * *$ & par_7 \\
X9 & $<---$ & Fator1 & .96 & .03 & 28.14 & $* * *$ & par_8 \\
X10 & $<---$ & Fator1 & .99 & .03 & 28.63 & $* * *$ & par_9 \\
X11 & $<---$ & Fator1 & .97 & .03 & 28.34 & $* * *$ & par_10 \\
X12 & $<---$ & Fator1 & 1.00 & .04 & 28.21 & $* * *$ & par_11 \\
X13 & $<---$ & Fator1 & .98 & .04 & 27.40 & $* * *$ & par_12 \\
X17 & $<---$ & Fator2 & 1.00 & & & & \\
X18 & $<---$ & Fator2 & .99 & .03 & 33.34 & $* * *$ & par_13 \\
X19 & $<---$ & Fator2 & .74 & .04 & 19.69 & $* * *$ & par_14 \\
X20 & $<---$ & Fator2 & .78 & .04 & 20.74 & $* * *$ & par_15 \\
X14 & $<---$ & Fator3 & 1.00 & & & & \\
X15 & $<---$ & Fator3 & .99 & .02 & 45.76 & $* * *$ & par_16 \\
X16 & $<---$ & Fator3 & .98 & .02 & 48.79 & $* * *$ & par_17 \\
\hline & & & & & &
\end{tabular}

Fonte: AMOS 22.0

Pesos Padronizados $\left(\beta_{i}\right)$

\begin{tabular}{|ccc|c|}
\hline & & & Estimate \\
\hline $\mathrm{X} 1$ & $<---$ & Fator1 & .96 \\
$\mathrm{X} 2$ & $<---$ & Fator1 & .97 \\
\hline
\end{tabular}


COSTA, Giovani Glaucio. Fatores essenciais de risco de uso de drogas por adolescentes: utilizando...

\begin{tabular}{|ccc|c|}
\hline & & & Estimate \\
\hline X3 & $<--$ & Fator1 & .97 \\
X4 & $<---$ & Fator1 & .97 \\
X5 & $<--$ & Fator1 & .96 \\
X6 & $<---$ & Fator1 & .96 \\
X7 & $<---$ & Fator1 & .97 \\
X8 & $<---$ & Fator1 & .96 \\
X9 & $<---$ & Fator1 & .96 \\
X10 & $<---$ & Fator1 & .97 \\
X11 & $<---$ & Fator1 & .97 \\
X12 & $<---$ & Fator1 & .96 \\
X13 & $<---$ & Fator1 & .96 \\
X17 & $<---$ & Fator2 & .97 \\
X18 & $<---$ & Fator2 & .98 \\
X19 & $<---$ & Fator2 & .89 \\
X20 & $<---$ & Fator2 & .90 \\
X14 & $<--$ & Fator3 & .99 \\
X15 & Fator3 & .99 \\
X16 & Fator3 & .99 \\
\hline
\end{tabular}

Fonte: AMOS 22.0

Correlações entre os Constructos

\begin{tabular}{|ccc|c|}
\hline & & & Estimate \\
\hline Fator1 & $<->$ & Fator2 & .62 \\
Fator1 & $<->$ & Fator3 & .14 \\
Fator2 & $<->$ & Fator3 & -.12 \\
\hline
\end{tabular}

Fonte: AMOS 22.0

Poder de Explicação das Variáveis Latentes s obre os Indicadores $\left(R^{2}\right)$ 
Revista de Ciências HUMANAS, Florianópolis, v. 50, n. 1, p. 209-240, jan-jun 2016

\begin{tabular}{|l|r|}
\hline & Estimate \\
\hline X16 & .98 \\
X15 14 & .97 \\
X20 & .97 \\
X19 & .82 \\
X18 & .80 \\
X17 & .96 \\
X13 & .95 \\
X12 & .92 \\
X11 & .93 \\
X10 & .93 \\
X9 & .93 \\
X8 & .93 \\
X7 & .93 \\
X6 & .94 \\
X5 & .92 \\
X4 & .93 \\
X2 & .93 \\
\hline
\end{tabular}

Fonte: $\operatorname{AMOS} 22.0$ 


\section{Variâncias}

\begin{tabular}{|c|ccccc|}
\hline & Estimate & S.E. & C.R. & P & Label \\
\hline Fator1 & 6.52 & .90 & 7.29 & $* * *$ & par_21 \\
Fator2 & 12.51 & 1.69 & 7.42 & $* * *$ & par_22 \\
Fator3 & 12.41 & 1.63 & 7.63 & $* * *$ & par_23 \\
e1 & .51 & .07 & 7.27 & $* * *$ & par_24 \\
e2 & .46 & .06 & 7.20 & $* * *$ & par_25 \\
e3 & .40 & .06 & 7.16 & $* * *$ & par_26 \\
e4 & .47 & .07 & 7.23 & $* * *$ & par_27 \\
e5 & .50 & .07 & 7.28 & $* * *$ & par_28 \\
e6 & .51 & .07 & 7.29 & $* * *$ & par_29 \\
e7 & .42 & .06 & 7.16 & $* * *$ & par_30 \\
e8 & .51 & .07 & 7.28 & $* * *$ & par_31 \\
e9 & .46 & .06 & 7.25 & $* * *$ & par_32 \\
e10 & .45 & .06 & 7.20 & $* * *$ & par_33 \\
e11 & .45 & .06 & 7.23 & $* * *$ & par_34 \\
e12 & .49 & .07 & 7.24 & $* * *$ & par_35 \\
e13 & .52 & .07 & 7.31 & $* * *$ & par_36 \\
e14 & .69 & .16 & 4.40 & $* * *$ & par_37 \\
e15 & .55 & .15 & 3.79 & $* * *$ & par_38 \\
e16 & 1.74 & .24 & 7.20 & $* * *$ & par_39 \\
e17 & 1.70 & .24 & 7.11 & $* * *$ & par_40 \\
e18 & .35 & .07 & 5.10 & $* * *$ & par_41 \\
e19 & .36 & .07 & 5.29 & $* * *$ & par_42 \\
e20 & .26 & .06 & 4.45 & $* * *$ & par_43 \\
\hline
\end{tabular}

Fonte: AMOS 22.0

A tabela 11 indica as estimativas dos pesos de regressão, os pesos padronizados de regressão, coeficientes de correlação entre os constructos, os coeficientes de explicação dos constructos sobre os indicadores e os termos de erros em variâncias. No caso do modelo hipotético, as estimativas individuais têm avaliações admiráveis. 
Os constructos são relativamente correlacionados, como era de ser esperar para os fatores de risco para o uso de drogas por jovens. Quanto ao CR, os pesos de regressão e variâncias de erros são todos significantes estatisticamente, uma vez que seus valores absolutos são maiores que o valor de 1,96.

Os pesos de regressão padronizados são altos, maiores do 0,7 e os coeficientes de explicação são admiráveis. Portanto, as estimativas individuais estão bem favoráveis.

Interpretação dos Resultados da MEE

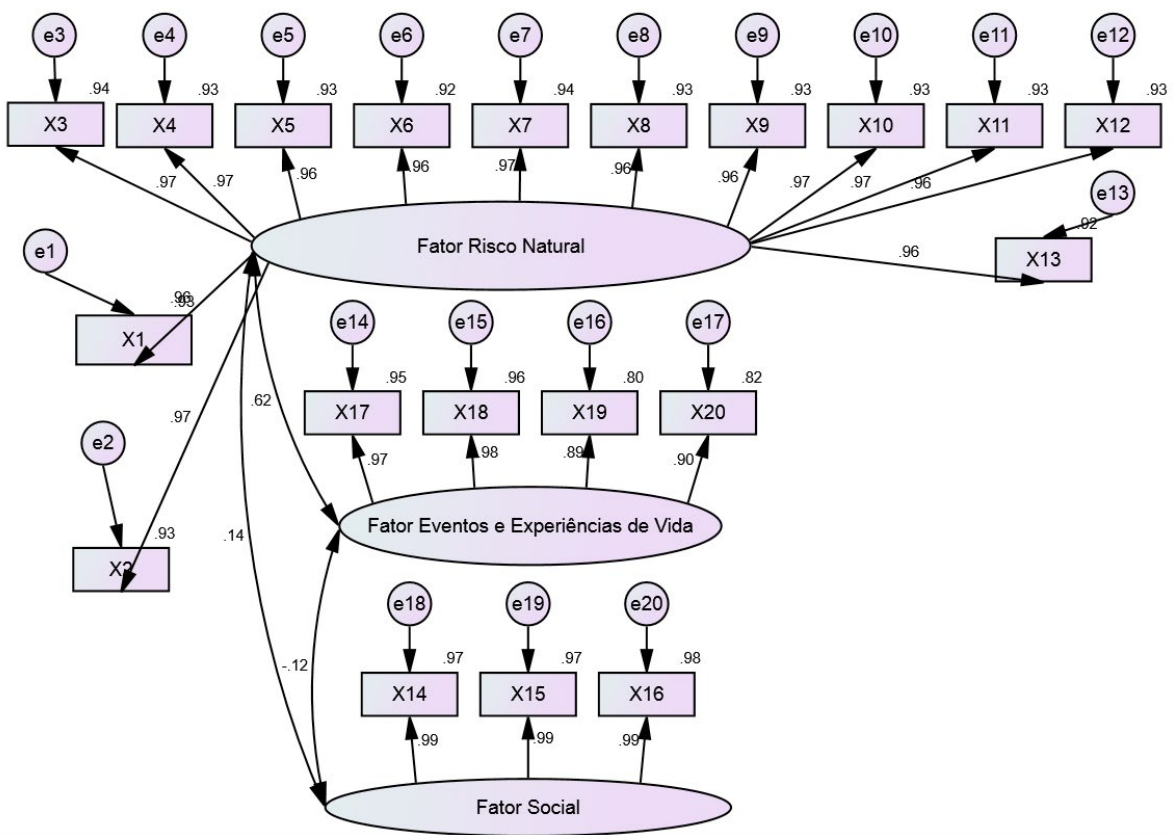

Fonte: AMOS 22.0

Observando a tabela 11 e o diagrama de caminhos do estudo, podemos fazer as seguintes interpretações:

- "Fator de Risco Natural", "Fator Evento e Experiência de Vida" e "Fator Social" têm admiráveis capacidades causais sobre seus indicadores, uma vez que os explicam com $\beta \mathrm{s}>0,7$;

- Existem correlações entre "Fator de Risco Natural", "Fator Evento e Experiência de Vida" e "Fator Social";

- "Fator de Risco Natural", "Fator Evento e Experiência de Vida" e "Fator Social" explicam proporções admiráveis de seus indicadores (coeficientes de explicação=R2 $\geq 0,5$ ). 
As próximas análise serão dedicadas às avaliações globais do modelo.

Tabela 12 - Teste do Qui-quadrado( CMIM/DF) CMIN

\begin{tabular}{|c|c|c|c|c|c|}
\hline Model & NPAR & CMIN & DF & $P$ & CMIN/DF \\
\hline Default model & 43 & 324.47 & 167 & .00 & 1.94 \\
\hline Saturated model & 210 & .00 & 0 & & \\
\hline $\begin{array}{l}\text { Independence } \\
\text { model }\end{array}$ & 20 & 5468.36 & 190 & .00 & 28.78 \\
\hline
\end{tabular}

Fonte: AMOS 22.0

No nosso estudo, o valor-p $=0,00<0,05$, nível de significância do estudo. Rejeita-se a hipótese nula de que as matrizes de dados(S) e estimada $(\Sigma)$ são estatisticamente iguais, o que indica inicialmente mau ajustamento do modelo proposto à base de dados. Contudo, este teste se desestabiliza em função do tamanho da amostra maior que o necessário. É fortemente recomendado realizar o teste CMIM/DF para confirmar esta decisão.

O CMIM/DF pode confirmar a aceitação ou não de bom ajuste do modelo à realidade. Embora não haja uma regra geral que aponte o valor mínimo aceitável para CMIM/DF, o critério comumente empregado é que essa razão seja menor do que 3.

A tabela 12 indica $\mathrm{CMIM} / \mathrm{DF}=1,94<3$, indicando na verdade o bom ajustamento do modelo. A matriz $\Sigma$ é uma estimativa de boa qualidade, isto implica que o modelo teórico que utilizou-se para representar os conceitos abstratos, que resumem as percepções dos técnicos a cerca das intensidades dos fatores individuais aumentarem as chances dos jovens usarem drogas é plausível com a realidade.

Tabela 13 - Teste da Bondade do Ajustamento AGFI.

Índice Ajustado de Qualidade de Ajuste

$A G F I$

\begin{tabular}{|c|cccc|}
\hline Model & RMR & GFI & AGFI & PGFI \\
\hline Default model & .44 & .80 & .75 & .64 \\
Saturated model & .00 & 1.00 & & \\
Independence model & 5.14 & .10 & .00 & .09 \\
\hline
\end{tabular}

Fonte: AMOS 22.0 
É uma extensão do GFI, ajustado através da raiz dos graus de liberdade do modelo proposto pelos graus de liberdade do modelo nulo (todos os parâmetros estruturais são fixados em zero). Valores superiores a 0,90 indicam níveis aceitáveis de ajuste. A tabela 13 indica $\mathrm{AGFI}=0,80 \approx 0,90$, o que pode ser considerado bom ajustamento dos dados.

Tabela 14 - Teste da Bondade do Ajustamento NFI

Índice de Ajuste Normalizado

\begin{tabular}{|l|rrrrr|}
\hline Model & $\begin{array}{r}\mathrm{NFI} \\
\text { Delta1 }\end{array}$ & $\begin{array}{r}\mathrm{RFI} \\
\text { rho1 }\end{array}$ & $\begin{array}{r}\text { IFI } \\
\text { Delta2 }\end{array}$ & $\begin{array}{r}\text { TLI } \\
\text { rho2 }\end{array}$ & CFI \\
\hline Default model & .94 & .93 & .97 & .97 & .97 \\
$\begin{array}{l}\text { Saturated model } \\
\text { Independence } \\
\text { model }\end{array}$ & 1.00 & & 1.00 & & 1.00 \\
\end{tabular}

Fonte: AMOS 22.0

Valores iguais ou superiores a 0,90 indicam níveis aceitáveis de ajuste. A tabela 14 indica $\mathrm{NFI}=0,94>0,90$, o que indica admirável ajustamento do modelo.

Tabela 15 - Teste da Bondade do Ajustamento PRATIO

Razão de Parcimônia

\begin{tabular}{|l|ccr|}
\hline Model & PRATIO & PNFI & PCFI \\
\hline Default model & .88 & .83 & .85 \\
Saturated model & .00 & .00 & .00 \\
Independence model & 1.00 & .00 & .00 \\
\hline \multicolumn{4}{c}{ Fonte: AMOS 22.0 }
\end{tabular}

O PRATIO não é um teste de bondade de ajustamento em si, e sim uma medida de parcimônia do modelo (modelo "enxuto"). Mas, como parcimônia, é fator de boa estimação; este teste é empregado como indicador de bondade de ajustamento. Os índices baseados em parcimônia são, usualmente, muito menores do que outras medidas de ajustamento. Valores superiores a 0,60 já são suficientes para considerar o ajuste satisfatório. Segundo a tabela 15, o modelo gerado tem um índice de parcimônia $\mathrm{PRATIO}=0,88>0,60$; o que indica bom ajustamento. 
Tabela 16 - Teste da Bondade do Ajustamento NCP

Parâmetros de Não-centralidade - NCP

\begin{tabular}{|l|rrr|}
\hline Model & NCP & LO 90 & HI 90 \\
\hline Default model & 157.47 & 110.26 & 212.48 \\
Saturated model & .00 & .00 & .00 \\
Independence model & 5278.36 & 5040.40 & 5522.67 \\
\hline
\end{tabular}

Fonte: AMOS 22.0

Resulta da tentativa de estatísticos em encontrar uma medida alternativa ao qui-quadrado que fosse menos sensível ao tamanho da amostra. Quanto menor seu valor, melhor, pois isso indica que as matrizes de dados (S) e a estimada $(\Sigma)$ não diferem consideravelmente. A tabela 16 evidencia um $\mathrm{NCP}=157,47>5$, um indicador, por este critério, de mau ajustamento. Contudo, é recomendável se fazer um balanço de todos os testes de bondade para se concluir finalmente sobre o nível de ajustamento global do modelo.

Tabela 17 - Teste da Bondade do Ajustamento RMSEA

Raiz do Erro Médio Quadrático de Aproximação

PCLOSE -RMSEA

\begin{tabular}{|l|rrrr|}
\hline Model & RMSEA & LO 90 & HI 90 & PCLOSE \\
\hline Default model & .09 & .07 & .10 & .00 \\
Independence model & .48 & .46 & .49 & .00 \\
\hline
\end{tabular}

Fonte: AMOS 22.0

A RMSEA é uma medida popular de ajustamento, parcialmente em razão de ser um dos índices de ajustamento menos afetado pelo tamanho da amostra, embora para amostras muito pequenas superestima a bondade de ajustamento. A RMSEA avalia quão o modelo se ajusta à matriz de covariância ou correlação da população, caso estivesse disponível. Os índices cujos valores sejam inferiores a 0,05 indicam bom ajustamento. Valores que variam de 0,05 a 0,08 são considerados aceitáveis. A Tabela 17 especifica RMSEA $=0,09$; fora dos limites de aceitação, o que revela mau ajustamento do modelo criado. Contudo, este resultado pode ser não significante estatisticamente. É recomendável que se teste a significância estatística do RMSEA.

Para ratificar o resultado, irá se testar a significância desta estimativa pelo PCLOSE. O valor-p associado ao RMSEA, PCLOSE, testa a hipótese nula de que a RMSEA é inferior a 0,05 . Se PCLOSE for maior que 0,05 ; a hipótese 
nula é aceita, concluindo-se que RMSEA computada é menor que 0,05 ; indicando bom ajustamento do modelo.

A tabela 17 aponta PCLOSE $=0,00<0,05$. Logo o valor de 0,09 é significante estatisticamente, indicando por este critério mau ajustamento do mode1o. Contudo, é recomendável se fazer um balanço de todos os testes de bondade para se concluir finalmente sobre o nível de ajustamento global do modelo.

Tabela 18 - Índices Preditivos de Ajustamento - AIC

\begin{tabular}{|l|rrrr|}
\hline Model & AIC & BCC & BIC & CAIC \\
\hline Default model & 410.47 & 428.18 & 531.74 & 574.74 \\
Saturated model & 420.00 & 506.47 & 1012.26 & 1222.26 \\
Independence model & 5508.36 & 5516.59 & 5564.76 & 5584.76 \\
\hline
\end{tabular}

Fonte: AMOS 22.0

Os Índices Preditivos de Ajustamento avaliam a extensão em que o modelo hipotético será validado em amostras futuras, de mesmo tamanho, extraídas da mesma população da qual foi extraída a amostra original do pesquisador. Os índices preditivos disponíveis no AMOS são: Critério de Informação Akaike (AIC), Critério de Informação BAYES (BIC) e Critério de Informação Akaike Consistente (CAIC). Para todo esse conjunto de índices, há comparação entre modelos, sendo considerado de melhor ajustamento os que exibirem os menores valores de AIC, BIC e CAIC.

Na tabela 18, o modelo default, comparado com os outros modelos, apresenta os menores índices preditivos, indicando boa validade e confiabilidade dos resultados da modelagem.

Tabela 19 - Índice de Bondade de Ajustamento ECVI

Índices de Validação Cruzada Esperada - ECVI

\begin{tabular}{|c|cccc|}
\hline Model & ECVI & LO 90 & HI 90 & MECVI \\
\hline Default model & $\mathbf{3 . 3 4}$ & $\mathbf{2 . 9 5}$ & $\mathbf{3 . 7 8}$ & $\mathbf{3 . 4 8}$ \\
Saturated model & 3.41 & 3.41 & 3.41 & 4.12 \\
Independence model & 44.78 & 42.85 & 46.77 & 44.85 \\
\hline
\end{tabular}

Fonte: AMOS 22.0

Os Índices de Validação Cruzada Esperada são uma aproximação da qualidade de ajuste que o modelo estimado apresentaria em outra amostra de dados, de igual tamanho. Não há intervalos especificados para valores aceitáveis, 
sendo mais bem utilizados na comparação com modelos alternativos. Na tabela 19, comparando com os modelos extremos, apresenta os menores índices, indicando boa validade e confiabilidade.

Tabela 20 - Índice de Bondade de Ajustamento (HOELTER)

\begin{tabular}{|c|cc|}
\hline Model & HOELTER & HOELTER \\
& .05 & .01 \\
\hline Default model & 76 & 81 \\
Independence model & 6 & 6 \\
\hline
\end{tabular}

Fonte: AMOS 22.0

O Índice de Ajustamento de HOELTER ou N Crítico indica o maior número para o tamanho da amostra para que se confiem nos resultados do Quiquadrado. $\mathrm{O}$ AMOS fornece o $\mathrm{N}$ crítico nos níveis de significância de $5 \% \mathrm{e}$ $1 \%$. Observando a tabela $20, \mathrm{~N}$ crítico $=202$, ao nível de $5 \%$ de significância, verificamos que para o teste do Qui-quadrado fosse considerado confiável seria necessária uma amostra de no máximo até 76 técnicos. A base de dados deste estudo tem 124 técnicos, logo está fora dos limites para que o CMIM seja preciso. Em consequência deste cenário, o teste do Qui-quadrado não foi confiável, como foi verificado na tabela 12 , ao nível de $5 \%$.

Realizando um balanço do estudo realizado, pode-se concluir que o modelo proposto na análise de modelagem de equações estruturais provavelmente é aceitável, o que se leva a validar o modelo teórico para o que sumariza os fatores de risco que aumentam, em diferente intensidade, a probabilidade de o evento ocorrer, à nível de $5 \%$ de significância.

Os fatores gerais "Fator de Risco Natural", "Fator Evento e Experiência de Vida" e "Fator Social", nesta ordem, são as variáveis latentes, os conceitos abstratos, que podem sumarizar os fatores individuais que facilitam o uso de drogas pelos adolescentes. Contudo, o modelo real do estudo é complexo e intrincado e qualquer tentativa de representá-lo é uma aproximação com diversas outras alternativas ou possibilidades.

\section{Conclusão}

$\mathrm{O}$ artigo objetivou realizar uma pesquisa de percepção junto a uma amostra não probabilística de 124 psicólogos e assistentes sociais. A pesquisa questionava, numa escala de 0 a 10 , a intensidade em que 20 fatores de risco individuais aumentariam a probabilidade de um adolescente vir a usar drogas. 
O estudo realizaria uma análise de confiabilidade, uma análise fatorial exploratória e uma modelagem de equações estruturais para verificar a existência de conceitos abstratos, identificá-los e confirmá-los. Estes conceitos, não medidos diretamente, seriam os fatores causais que explicariam as percepções dos técnicos a cerca das intensidades dos fatores individuais estarem condicionados ao uso de droga por jovens.

"Fator de Risco Natural", "Fator Evento e Experiência de Vida" e "Fator Social", nesta ordem, são os fatores latentes, os conceitos abstratos, confirmados como resumo teórico conceitual da percepção dos especialistas quanto aos fatores de risco gerais para o consumo de drogas não lícitas por adolescentes. Estes novos eixos temáticos resumem em $94,5 \%$ a variação das opiniões auferidas pelos pesquisados no estudo. A modelagem de equações estruturais, em seu balanço geral, atestou aceitável aderência dos dados à realidade populacional e ratificou significância das forças das relações causais estimadas.

O estudo visou buscar apoio do método científico para os conceitos essenciais que resumem os fatores de risco individuais que facilitam o uso de drogas por jovens. Com a consecução dos resultados, o referido apoio pode ser considerado pertinente e o objetivo do estudo alcançado. Acredita-se que o mérito deste estudo foi procurar aumentar ou confirmar o conhecimento dos fatores individuais de risco que ocasionam o uso de drogas por adolescentes, auxiliando a que se chegue a um provável consenso sobre o uso de drogas pelos jovens. A investigação é meramente preliminar - o ideal seria uma amostra com maior representatividade - mas abre caminhos para estudos mais generalizáveis sobre a temática estudada.

\section{Referências}

ARTHUR, MW; HAWKINS, JD; POLLARD, JÁ; CATALANO, RE; BAGLIONI, Jr. Measuring risk and protective factors for substance use, delinquency, and other adolescent problem behaviors. Evaluation Review [S.1.\}, v. 26, n.6, p.575-601, 2002.

ASSIS, SG; AVANCI, JQ; SILVA, CMFP; MALAQUIAS, JV; SANTO, NC; OLIVEIRA, RVC. A representação social do adolescente: um passo decisivo na promoção da saúde. Ciência \& Saúde Coletiva, [S.1.], v. 8, n.3, p. 669-680. 2003.

BENTLER, Peter M.; WU, Eric J.C. EQS 6 for windowsuser's guide. Encino: Multivariate Software Inc., 2002.

BOLLEN, Kenneth A. Structural equations with latent variables. New York: John Wiley \& Sons, Inc., 1989.

BYRNE, Barbara M. Structural equation modeling with EQS and EQS/windows: basic concepts, applications and programming. Thousand Oaks: Sage Publications, 1994. 
BUCHABQUI J; ABECHE, A., BRIETZE, E. - Assistência pré-natal.In: FREITAS, Fernando; MARTINS-COSTA, Sérgio H.; RAMOS, José Geraldo Lopes; MAGALHÃES, José Antônio. (Orgs). Rotinas em obstetrícia .Porto Alegre: Artes Médicas, 2001, p. 23-37.

CHILCOAT, HD; ANTHONY, JC. Impact of parenting monitoring on initiation of drug use through late childhood. Journal of the American Academy of Child and Adolescent Psychiatry, [S.1.], v. 35, n. 1, p. 91-100. 1996.

DUNCAN, Otis Dudley. Path analysis: sociological examples. In: BLALOCK JR, H.M. (Org). Causal models in the social sciences. Chicago: Aldine Publishing Company, 1971, p. 115-138.

ELLOCKSON, PL; MORTON, SC. Identifying adolescents at risk for hard drug use: racial/ ethnic variations. Journal of Adolescent Health, [S.1.], v. 25, n.?, p. 382-395, 1999.

FRANCIS, HH - Delayed childbearing. IPPF Medical Bulletim, [S.1.], v. 19, n. 3, p. 3-4, 1985.

HOX, J. J.; BECHGER, T. M. An Introduction to structural equation modeling. Family Science Review, Minneapolis, v. 11, n.? p. 354-373, 1998.

HOYLE, R. H.; SMITH, G. T. Formulating clinical research hypotheses as structural equation models: A conceptual overview. Journal of Consulting and Clinical Psychology, American Psychological Association, Washington, v. 62, n. 3, p. 429-440, c1994.

KAPLAN, David. Structural equation modeling: foundations and extensions. Thousand Oaks: Sage Publications, 2000.

KLEM, L. Structural equation modeling. In: GRIMM, L.G.; YARNOLD, P.R. (Eds.).Reading and understanding more multivariate statistics. Washington, D.C.: American Psychological Association, c2000.

KLINE, Rex B. Principles and practice of structural equation modeling. New York: The Guilford Press, 1998.

PATTON, LH. Adolescent substance abuse. Risk factors and protective factors. Pediatric Clinics of North America, [S.1.], v. 42, n.2, p. 283-293, 1995.

SCHENKER, M; MINAVO, MCS. A implicação da família no uso abusivo de drogas: uma revisão crítica. Ciência \& Saúde Coletiva, [S.1.], v. 8, n.1, p. 299-306. 2003.

Submisão em: 08/09/2014

Aceite em: 06/04/2016

Giovani Glaucio Costa é pós-doutor em Sociologia, Análises Estatísticas Multivariadas, pelo Instituto Universitário de Pesquisas do Rio de Janeiro, na área de criminologia infanto-juvenil com a pesquisa "Perfil biopsicossocial do adolescente em conflito com lei e fatores relacionados à prática de atos infracionais por parte destes adolescentes: modelagem estatístico-inferencial da delinquência juvenil no Estado do Rio de Janeiro (2008)". Endereço para correspondência: Rua Duvivier, 96, ap. 804, Copacabana, Rio de Janeiro/RJ. CEP 22020-020. E-mail: giovaniglaucio@,hotmail.com e giovaniglaucio@ufrrj.br 